\title{
Hyponatraemia as the leading symptom of tuberculous meningitis in a 14-month-old girl
}

\author{
Ewa Błaszczyk ${ }^{1}$, Małgorzata Firek-Pędras ${ }^{1}$, Joanna Sordyl' ${ }^{1}$ Elżbieta Berdej-Szczot ${ }^{1}$, \\ Magdalena Machnikowska-Sokołowska², Katarzyna Gruszczyńska², Ewa Czerwińska ${ }^{3}$ \\ 'Department of Pediatrics and Pediatric Endocrinology, Faculty of Medical Sciences in Katowice, Medical University of Silesia \\ in Katowice, Poland \\ 2Department of Imaging Diagnostics, Department of Radiology and Nuclear Medicine, Faculty of Medical Sciences \\ in Katowice, Medical University of Silesia in Katowice, Poland \\ ${ }^{3}$ Department of Paediatrics and Infectious Diseases, Wroclaw Medical University, Wroclaw, Poland
}

\section{ABSTRACT}

Tuberculous meningitis (TBM) is a rare form of tuberculosis (TB), however can lead to severe neurological deficits or even to death. TBM remains a diagnostic challenge because of nonspecific symptoms and subacute course. However, it is worth remembering hyponatraemia is a relatively common symptom in neuroinfections, especially in TBM. We report the case of 14-month-old girls admitted to hospital with fever, vomiting and loose stools, with persistent laboratory hyponatraemia. Despite the initial lack of specific symptoms and history suggesting contact with person suffering from TB, the TBM was recognized in the first phase of the disease before evident symptoms of the central nervous system.

\section{KEY WORDS:}

CSWS, SIADH, tuberculous encephalitis, head MRI.

\section{INTRODUCTION}

According to WHO report, an estimated 10.0 million people fell ill with tuberculosis (TB) in 2018, of which 1.2 million among HIV-negative people died. Children aged $<15$ years accounted for $11 \%$ of all TB cases [1]. In Poland, in 2017 there were 5,535 new cases of TB, of which the vast majority (95.6\%) was pulmonary TB [2]. However pulmonary tuberculosis accounts for $80 \%$ of cases in the world, TB can involve extrapulmonary disease, such as meningitis and miliary or disseminated disease. Tuberculous meningitis (TBM) is an especially devastating form of TB that causes death or severe neurological deficits in more than one-half of persons affected [3]. In 2018, in Poland 2 cases of TBM were registered in chil- dren aged 0-14 [4]. Due to the variable nature of symptoms, TBM still remains a diagnostic challenge.

We present a case of a 14-month-old girl with tuberculous encephalo-meningitis diagnosed on the basis of head MRI in search of cause of persistent hyponatraemia.

\section{CASE REPORT}

A 14-month-old girl with Turner syndrome diagnosed in the neonatal period was transferred to the Department of Pediatrics and Pediatric Endocrinology in Katowice from peripheral community hospital due to suspected pneumonia and syndrome of inappropriate antidiuretic hormone hypersecretion (SIADH).

\section{ADDRESS FOR CORRESPONDENCE:}

Ewa Błaszczyk, Department of Pediatrics and Pediatric Endocrinology, Faculty of Medical Sciences in Katowice,

Medical University of Silesia in Katowice, 16 Medyków St., 40-752 Katowice, Poland, ORCID: 0000-0002-0630-4780,

e-mail: ewa_p2@vp.pl 
According to the history, a child was from the $3^{\text {rd }}$ pregnancy, born by natural delivery at 36 week of pregnancy (uncontrolled pregnancy) with body weight $2180 \mathrm{~g}$, body length $45 \mathrm{~cm}$, head circumference $32 \mathrm{~cm}$, on the Apgar score received 7/7/9/10 points. After delivery, girl was hospitalized in the Neonatal Pathology Department, where Turner syndrome, hemodynamically insignificant foramen ovale and muscular hypotonia were diagnosed. Girl was vaccinated BCG in accordance with the Polish Vaccination Calendar (premature babies, if they have no other contraindications, are vaccinated against tuberculosis after reaching a body weight of over $2000 \mathrm{~g}$ ). In family history - father suffers from bronchial asthma and type 2 diabetes mellitus.

Six days before admission to our hospital, girl was hospitalized in peripheral hospital because of vomiting and loose stools. During the first three days of hospitalisation, the girl was feverish. Intravenous liquids, probiotic and antipyretics were used in the treatment. Because of hyponatraemia, oral fluid supply was limited. The abdominal ultrasound image was normal. On the $6^{\text {th }}$ day, the girl's condition began to deteriorate - vomiting intensified, doctors observed apathy and excessive drowsiness, child was weakened. Physical examination revealed single thick rales on the right side of the lungs. In laboratory tests, negative inflammation parameters persisted, however hyponatraemia was attracting the attention. Rotavirus and adenovirus antigens were not found in feces. Chest $\mathrm{X}$-ray and ultrasound of the lungs showed discrete shadow in the middle field on the right lung. An intravenous antibiotic (amoxicillin + clavulanic acid) was added to the treatment, the sodium deficits were corrected (5\% glucose with the addition of $10 \% \mathrm{NaCl}$ and $15 \% \mathrm{KCl}$ ) and the patient was transferred to our hospital, with suspected SIADH syndrome in the course of pneumonia - periodic episodes of vomiting, excessive apathy and drowsiness were treated as secondary to hyponatraemia.

In the day of admission, typical physical phenotypic features of Turner syndrome (hypertelorism, widely spaced nipples, shortening of the $4^{\text {th }}$ metacarpal bones), muscle hypotension and systolic murmur over the heart were found in the physical examination. There were no auscultatory changes over the lung fields and no signs of infection in the upper respiratory tract, all meningeal signs were negative. Blood pressure measurements were normal. In laboratory tests - inflammation parameters as well as renal and hepatic parameters were within the range. Urine and serum osmolality was normal, however urine osmolality was over $>100 \mathrm{mosmol} / \mathrm{kg}$ (Table 1 ). Upon admission to our department, sodium levels were normal, however, tendencies to hyponatraemia were observed in the subsequent days of hospitalisation (Fig. 1). Concentrations of other ions were within the range. Intravenous liquids with the use of $5 \%$ glucose with the addition of $10 \% \mathrm{NaCl}$ and $15 \% \mathrm{KCl}$, in proportion depending on the laboratory parameters, were used as well
TABLE 1. Laboratory results

\begin{tabular}{|c|c|}
\hline Parameter & Result \\
\hline WBC & $13.90 \times 10^{3} / \mathrm{ul}$ \\
\hline $\mathrm{RBC}$ & $4.86 \times 10^{6} / \mathrm{ul}$ \\
\hline PLT & $511 \times 10^{3} / \mathrm{ul}$ \\
\hline Neu & $65.5 \%$ \\
\hline Limf & $23.4 \%$ \\
\hline Mono & $10.8 \%$ \\
\hline Albumin & $41.8 \mathrm{~g} / \mathrm{l}$ \\
\hline AST & $23 \mathrm{U} / \mathrm{I}$ \\
\hline Total protein & $65.0 \mathrm{~g} / \mathrm{l}$ \\
\hline CRP & $1.1 \mathrm{mg} / \mathrm{l}$ \\
\hline Uric acid & $2.4 \mathrm{mg} / \mathrm{dl}$ \\
\hline Creatinine & $0.17 \mathrm{mg} / \mathrm{dl}$ \\
\hline Urea & $6 \mathrm{mg} / \mathrm{dl}$ \\
\hline Procalcitonin & $0.07 \mathrm{ng} / \mathrm{ml}$ \\
\hline Cortisol 8:00 & $38.50 \mu \mathrm{g} / \mathrm{dl}$ \\
\hline Cortisol 24:00 & $10.40 \mu \mathrm{g} / \mathrm{dl}$ \\
\hline $\mathrm{Na}$ & $137 \mathrm{mmol} / \mathrm{l}$ \\
\hline $\mathrm{Cl}$ & $105 \mathrm{mmol} / \mathrm{l}$ \\
\hline$P$ & $1.11 \mathrm{mmol} / \mathrm{l}$ \\
\hline $\mathrm{Mg}$ & $0.98 \mathrm{mmol} / \mathrm{l}$ \\
\hline K & $4.42 \mathrm{mmol} / \mathrm{l}$ \\
\hline $\mathrm{Ca}$ & $2.49 \mathrm{mmol} / \mathrm{l}$ \\
\hline Serum osmolarity & $287.0 \mathrm{~m} 0 \mathrm{sm} / \mathrm{kg} \mathrm{H}_{2} \mathrm{O}$ [n: 275-305] \\
\hline Urine osmolarity & $146.0 \mathrm{~m} 0 \mathrm{sm} / \mathrm{kg} \mathrm{H}_{2} \mathrm{O}$ [n: 50-1200] \\
\hline K (urine) & $4.0 \mathrm{mmol} / \mathrm{l}[\mathrm{n}: 17-83]$ \\
\hline $\mathrm{Na}$ (urine) & $51 \mathrm{mmol} / \mathrm{l}$ [n: 27-147] \\
\hline
\end{tabular}

AST - aspartate transaminase, CRP - C-reactive protein, Na - sodium, Cl - chloride, $P$ - phosphate, $\mathrm{Mg}$ - magnesium, $\mathrm{K}$ - potassium, $\mathrm{Ca}$ - calcium

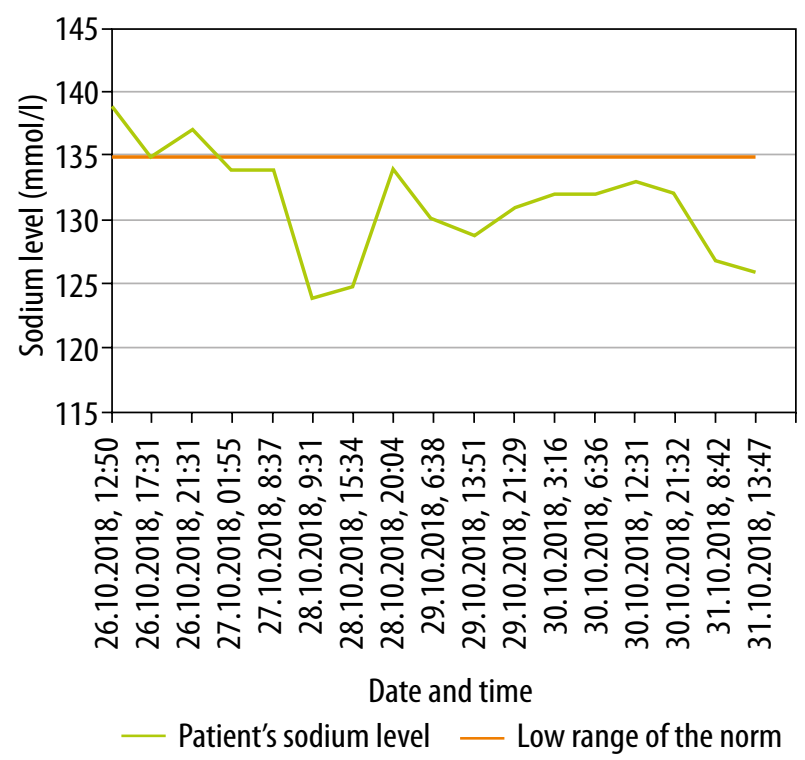

FIGURE 1. The patient's sodium level during hospitalisation 


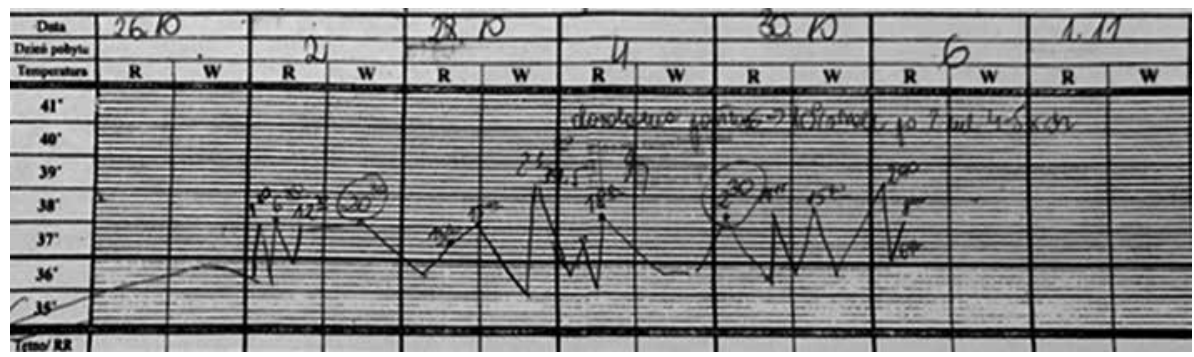

FIGURE 2. The patient's body temperature chart

as symptomatic treatment. The diagnostic was extended by measurement of 24-hour-profile of cortisol concentration - we noted elevated levels (Table 1). Glucose profile was determined and normal glucose levels were found.

The girl was still feverish (Fig. 2), but we did not find a clear source of infection in the physical examination. The child's condition during the day was variable - periodically, most often in the morning, we observed symptoms of apathy, drowsiness and vomiting correlating with the severity of hyponatraemia. In the afternoon, the child was lively and eating meals without vomiting. In addition, despite intensive equalisation of sodium ions ( $5 \%$ glucose with the addition of $10 \% \mathrm{NaCl}$ depending on the observed sodium concentrations), we did not achieve normonatraemia (Fig. 1). Because of observed symptoms and suspected central nervous system background, head MRI was performed. Investigation showed strong contrast enhancement of the thickened meninges on the surface of left temporal lobe (Fig. 3A-F), without any abnormality in native $\mathrm{T} 1 / \mathrm{w}$ sequences. Regarding the hypophysis, on thin T1/w saggital projections the typical high signal of posterior lobe of the hypophysis was not visible, however the enhancement of the anterior lobe was normal. (Fig. 3G and $\mathrm{H}$ ). The radiolological diagnosis suggested tuberculous meningitis or, less likely, fungal or sarcoidosis aetiology. Third generation cephalosporin, fluconazole and acyclovir were used in the treatment. Under general anaesthesia, lumbar puncture was performed, obtaining a cerebrospinal fluid (CSF) with parameters suggestive of tuberculous meningitis - cytosis with lymphocyte pre-

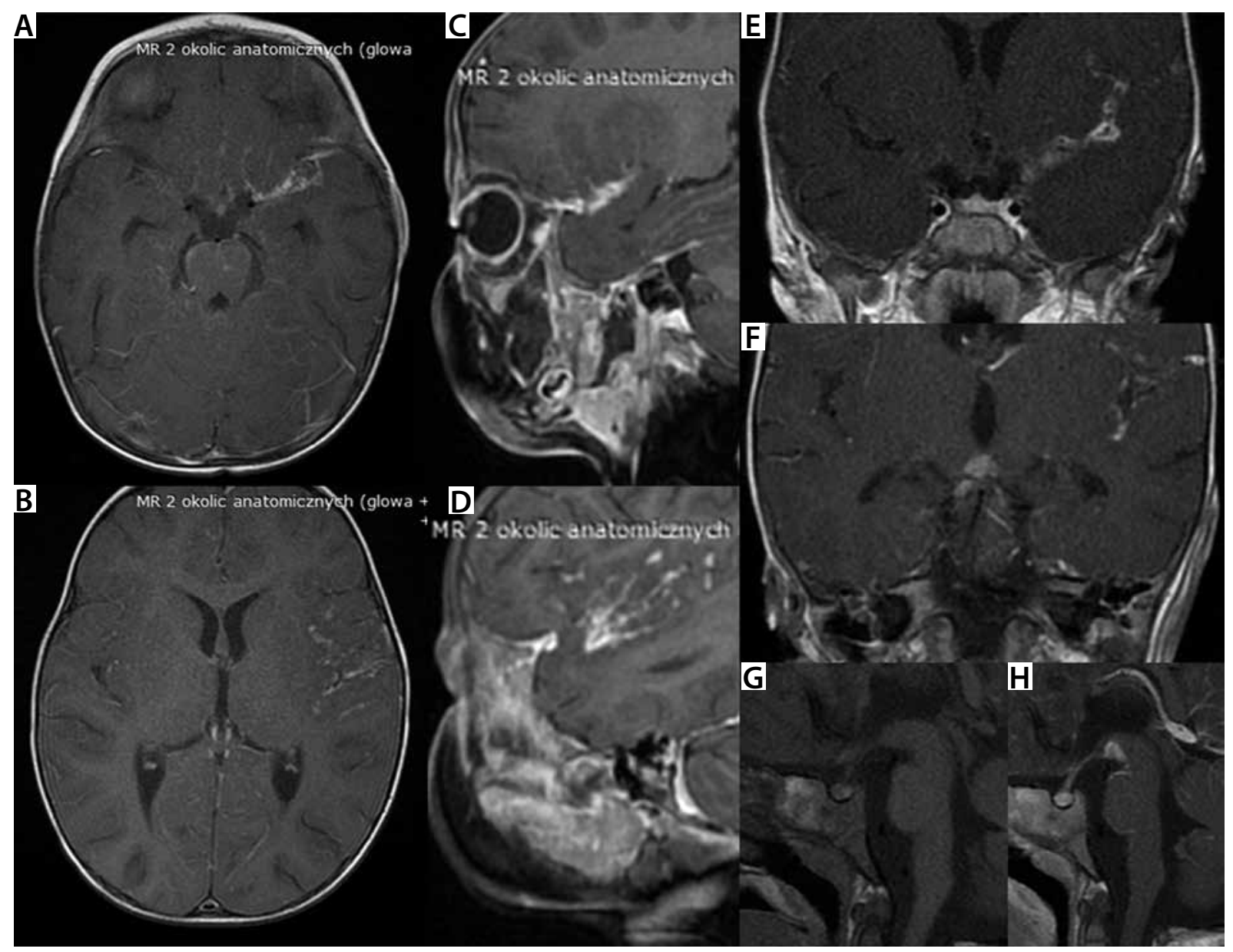

FIGURE 3. MRI of the central nervous system 
dominance, reduced glucose and moderate increase in protein (Table 2). Rapid latex tests for N. meningitidis, S. pneumoniae, H. influenzae, S. agalactiae, E. coli in CSF were negative. Due to suspicion of tuberculous aetiology, the child was referred for further treatment to an appropriate tuberculosis treatment centre.

After discharge from our department, the results of the previously ordered tests were obtained: the RT-PCR DNA test for Mycobacterium tuberculosis in CSF was positive, similarly to the interferon gamma release assay (QuantiFERON ${ }^{\circledR} \mathrm{TB}$ Gold) serum test result. No presence of fungi (Candida, Aspergillus) was found in CSF.

We found out that in the Clinic of Paediatrics and Infectious Diseases in Wroclaw 3 anti-tuberculosis drugs were used in treatment - isoniazid, rifampicin and pyrazinamide (during the entire hospitalisation period, 26 days). Antibiotic (ampicillin) and glucocorticosteroid (dexamethasone) were administered until obtainment a positive PCR result for tuberculosis and a positive TB_spot result from our clinic (3 days), as well as a negative result of the cerebrospinal fluid test for listeriosis. Moreover, the sodium level was balanced with the addition of food supplementation and $1.5 \mathrm{ml}$ of $10 \% \mathrm{NaCl}$ twice a day, getting normonatraemia on the third day of hospitalisation.

After a few days, the girl's clinical condition improved. However, on the $12^{\text {th }}$ day of hospitalisation, the girl developed a forced head position to the right and weakening of the muscular strength of the right hand. In shoulder $\mathrm{X}$-ray abnormalities were not described and neck ultrasound showed no changes. MR of the head and neck in comparison to our study revealed a moderate progression of infiltrative granulomatous lesions of the meninges of the basal cerebral tuberculosis, slight subacute lacunar ischemic lesions in the left thalamus and the area of the basal ganglia on the left as a complication. Besides, the CNS imaging was comparable to the one previously described.

The mentioned clinical symptoms gradually disappeared and after 26 days of hospitalisation girl was sent for further treatment to a smaller centre of pulmonology. Anti-mycobacterial treatment was continued for 4 weeks (ethambutol, isoniazid, rifampicin, pyrazinamide), 10\% $\mathrm{NaCl}$ was administered orally and steroid therapy was introduced. Patient was discharged home with the recommendation to continue the treatment (isoniazid, rifampicin, pyrazinamide, dexamethasone, $10 \% \mathrm{NaCl}$ orally).

After next 4 weeks of treatment at home, girl was admitted to hospital for evaluation of treatment. During hospitalisation, sodium levels were normal, steroids were gradually discontinued and sodium supplementation was totally reduced. The girl was referred to a further outpatient clinic with the recommendation to continue the treatment with rimfampicin and isoniazid.

Currently, the girl is 3 years old and has no neurological deficits after TBM.
TABLE 2. Cerebrospinal fluid parameters

\begin{tabular}{|l|c|}
\hline Parameter & Result \\
\hline Colour & Colourless \\
\hline Appearance & Clear \\
\hline Cells & $\begin{array}{c}84 / 1 \mu \mathrm{l}(70 \% \text { lymp, } 30 \% \text { neu }) \\
70 \% \text { limf, } 30 \% \text { seg }\end{array}$ \\
\hline Glucose & $30.0 \mathrm{mg} / \mathrm{dl}[\mathrm{n}: 40.0-70.0]$ \\
\hline Chloride & $115.0 \mathrm{mmol} / \mathrm{I}[\mathrm{n}: 110.0-130.0]$ \\
\hline Total protein & $96.0 \mathrm{mg} / \mathrm{dl}[\mathrm{n}: 10.0-40.0]$ \\
\hline Lactic acid & $4.36 \mathrm{mmol} / /$ [n: $1.1-2.8]$ \\
\hline Culture & Negative \\
\hline $\begin{array}{l}\text { RT-PCR DNA test } \\
\text { for } M . \text { tuberculosis }\end{array}$ & Positive \\
\hline
\end{tabular}

lymp - lymphocytes, neu - neutrophils

\section{DISCUSSION}

Tuberculous meningitis complicates approximately $0-3 \%$ of untreated TB infections in children. It is most common in children between 6 months and 4 years of age. More commonly the signs and symptoms progress slowly over weeks and are divided into 3 stages.

The $1^{\text {st }}$ stage typically lasts $1-2$ weeks and characterised by non-specific signs such fever, headache, vomiting, irritability, drowsiness and malaise. Focal neurologic signs are absent. Majority of patients diagnosed and treated in this stage have an excellent outcome.

In $2^{\text {nd }}$ stage lethargy, seizures, nuchal rigidity, positive Kernig and Brudzinski signs, vomiting and cranial nerves palsies are common.

The $3^{\text {rd }}$ stage is marked by coma, hemi- or paraplegia, decerebrate posturing and death.

The most important laboratory test confirming diagnosis of TBM is examination of lumbar CSF with typical changes: leukocyte $20-1000$ cells $/ \mathrm{ml}$ with $60 \%$ predominance of lymphocytes, glucose - less than $60 \%$ of level in serum, protein level usually higher than $100 \mathrm{mg} / \mathrm{dl}$. Acidfast stain is positive only in $20-37 \%$ of cases. Detection of Mycobacterium tuberculosis DNA by PCR method and interferon gamma release assay confirm diagnosis TB $[5,6]$.

Diagnosis of TBM in our patient created diagnostic difficulties: the girl was vaccinated BCG in the neonatal ward, before being sent home, epidemiological family history about contact with person suffering from TB was negative, leading symptom drawing our attention was persistent hyponatraemia. Thanks to the correct assessment of head MRI diagnosis of TBM was established.

According to literature determining the source of tuberculosis infection is often impossible [7]. Only $10 \%$ of children with TBM are diagnosed in the first phase [8], what is connected with the lack of symptoms from the central nervous system in this phase. Because of many dia- 
gnostic difficulties, it is proposed to use scoring questionnaires to determine the probability of TBM. According to the 2010 consensus, all patients with features suggesting meningitis (headache, irritability, vomiting, fever, neck stiff ness, convulsions, focal neurological deficits or altered consciousness) should be evaluate toward TBM. Duration of neurological symptoms for more than 5 days is the most informative clinical criterion [9]. As an additional clue, TBM is usually reported in children under the age of 5 with relatively few cases in school-age or adolescence [7].

In our case, we observed non-specific symptoms such as fever, irritability, vomiting and in laboratory test we noted hyponatraemia. All these symptoms in the first place suggested gastroenteritis. Only persisting ionic disorders were a factor to perform further diagnostics. We ordered measurement of 24-hour-profile of cortisol concentration to assess the function of the adrenal glands. We noted elevated levels of cortisol. In congenital adrenal hyperplasia that we would expect, apart from hyponatraemia, a decreased concentration of cortisol, which made this diagnosis impossible. We determined the clinical assessment of extracellular fluid volume status and performed the determination of plasma and urine osmolality. All parameters were within the our hospital laboratory range, however urine osmolality was over $>100 \mathrm{mosmol} / \mathrm{kg}$ (Table 1 ).

According to the literature, in TBM cases, high rates of hyponatraemia was noticed (79\%) [10]. Nevertheless, hyponatraemia may occur in a variety of CNS disorders and most of the literature concerns descriptions of adults, where it appears to be a more common disorder than in children. Among the causes of hyponatraemia during neuroinfection, two syndromes with hypotonic hyponatraemia may occur - SIADH and cerebral salt-wasting syndrome (CSWS). It is believed that SIADH is the most common aetiology for hyponatraemia [11], however, the incidence of CSWS may be underestimated due to the recognition of some cases as SIADH [12]. To diagnose SIADH other hyponatraemic conditions should be excluded; low plasma osmolality $(<275 \mathrm{mosmol} / \mathrm{kg})$ and inappropriate urine concentration (urine osmolality $>100 \mathrm{mosmol} / \mathrm{kg}$ ) should be found [13]. Contrary to the mentioned criteria our patient had serum osmolality within the range. The diagnosis of CWSW was not possible because of our patient's euvolaemia the normal serum osmolality [14].

Difficulty in distinguishing the cause of hyponatraemia may be due to mild hyponatraemia. Although the diagnosis of SIADH seemed more probable, we were ultimately unable to make this diagnosis for the child.

\section{CONCLUSIONS}

TBM remains a diagnostic challenge. We rarely think of tuberculous meningitis, especially in vaccinated children. What is more, the symptoms of the disease are subacute and non-specific.
In TBM it is important to start appropriate treatment early to prevent death and the development of neurological and psychological complications.

It is worth remembering hyponatraemia can be one of symptoms in neuroinfections, including TBM.

\section{ACKNOWLEDGEMENTS}

We would like to thank Professor Leszek Szenborn the Head of the Clinic of Paediatrics and Infectious Diseases in Wroclaw for his help in collecting information about the patient's course of treatment.

\section{DISCLOSURE}

The authors declare no conflict of interest.

\section{REFERENCES}

1. World Health Organization. WHO TB Report. WHO Libr Cat Data World 2019, 7.

2. WHO Regional Office for Europe/European Centre for Disease Prevention and Control. Tuberculosis surveillance and monitoring in Europe 2019-2017 data. WHO Regional Office for Europe, Copenhagen 2019.

3. Lasso BM. Tuberculous meningitis: Tips for diagnosis and proposals for treatment. Rev Chil Infectol 2011; 28: 238-247.

4. Korzeniewska-Koseła M. Gruźlica i choroby układu oddechowego w Polsce w 2019 r. Instytut Gruźlicy i Chorób Płuc, Warszawa 2020.

5. Kliegman RM. Tuberculosis. In: Nelson Textbook of Pediatrics, $20^{\text {th }}$ ed. Elsevier 2016, 1445-1460.

6. Augustynowicz-Kopeć E, Demkow U, Grzelewska-Rzymowska I, et al. Guidelines of Polish Respiratory Society concerning diagnosis, treatment and prevention of tuberculosis in adults and in child. Pneumonol Alergol Pol 2013; 81: 325-379.

7. Christie LJ, Loeffler AM, Honarmand S, et al. Diagnostic challenges of central nervous system tuberculosis. Emerg Infect Dis 2008; 14: 1473-1475.

8. Yaramiş A, Gurkan F, Elevli M, et al. Central nervous system tuberculosis in children: a review of 214 cases. Pediatrics 1998; 102: E49.

9. Marais S, Thwaites G, Schoeman JF, et al. Tuberculous meningitis: a uniform case definition for use in clinical research. Lancet Infect Dis 2010; 10: 803-812.

10. Davis LE, Rastogi KR, Lambert LC, Skipper BJ. Tuberculous meningitis in the southwest United States. Neurology 1993; 43: 1775.

11. Babaliche P, Madnani S, Kamat S. Clinical profile of patients admitted with hyponatremia in the medical intensive care unit. Indian J Crit Care Med 2017; 21: 819-824.

12. Palmer BF. Hyponatremia in patients with central nervous system disease: SIADH versus CSW. Trends Endocrinol Metab 2003; 14: 182-187.

13. Laczi F. Etiology, diagnostics and therapy of hyponatremias. Orv Hetil 2008; 149: 1347-1354.

14. Garkowski A, Zajkowska J, Czupryna P. Hiponatremia w przebiegu neuroinfekcji - zespół nieadekwatnej syntezy wazopresyny i mózgowy zespół utraty soli. Neurologia po Dyplomie 2015; 3: 23-28. 